David Gordon, grandson of the present Earl, has with his wife done much to foster a love of music in the north-east. For more than forty years students and graduates of the University have staged a theatre show during their Charities Week. When the British Association visited Aberdeen in 1934 they presented the pageant "Town and Gown" in honour of the visit, and this year, during the first week of the meeting, they are to stage a revue under the title "Element of Surprise".

Following the usual pattern of British Association. meetings, a special programme has been arranged for young people. In the High School for Girls there will be a Science Fair, which will be opened on Thursday morning by the President. Here there will be on display exhibitions and experiments devised by the pupils of the secondary schools and colleges of Aberdeen and the neighbouring counties. Of the many items listed among the projects is one, by the Gordon Schools, Huntly, under the intriguing title of "There is more to Transistors than Cliff Richard". The opening ceremony will be followed later in the morning by a reception at which pupils and staff will have an opportunity to meet the President and Officers of the Association. Among the many other items arranged for the young people is a 'Brains Trust' when a panel of scientists will attempt to answer questions sent in by the pupils, and a full programme of lectures including the York Lecture by Sir Raymond. Priestley, president of the Royal Geographical Society, on "Antarctic Exploration Yesterday and To-day". Sponsored by Section X there will be on Monday morning a series of talks, under the title "Science in the Sixth Form", given by seven secondary school pupils.

Aberdeen looks forward with interest and with pleasure to its fourth visit from the British Association, which the organizers hope will be even more successful than the three previous meetings.

\title{
OBITUARIES
}

\section{Dr. Theodore von Kármán, For.Mem.R.S.}

Theodore von KÁrmán was born in Budapest on May 11, 1881, son of Prof. Maurice von Kármán, a distinguished pedagogue and philosopher, and Helene Konn. After graduation in 1902 with highest honours as a mechanical engineer from the Budapest Royal Technical University, he spent the next four years in Hungary, teaching at the University and performing theoretical research on machine design problems for Ganz and Company.

The next six years were spent in study in London, Paris and Göttingen. His first direct contact with aeronautics occurred in Paris in 1907 when he saw Henri Farman fly a circular one-kilometre course. He settled for a time at the University of Göttingen to work with L. Prandtl, receiving a Ph.D. degree in 1908. His dissertation on the buckling strength of straight columns was the first of many major contributions. In this communication he set forth the double-modulus theory of column behaviour under loads which stress the column material beyond the elastic limit. Von Kármán continued as a teaching Fellow until 1912. During this period, stimulated by observing the difficulty of his colleague, Hiemenz, in obtaining symmetrical flow of water about a circular cylinder, he developed and published in three communications in $191 \mathrm{I}$ and 1912 his well-known theory of the unsymmetrical vortex arrangement in the wake of a cylinder, commonly known as the Kármán vortex trail.

In 1912 von Kármán accepted an invitation to become professor of aeronautics and mechanics and director of the Aerodynamic Institute in the Technical University of Aachen. The Aachen period was one of rapid growth to eminence on the part of the man and the Institute. His interests turned largely toward fluid mechanics. Some of his most notable contributions dealt with the stability of laminar flow, the theory of turbulence, wing theory, pressure distribution on airship hulls and the Kármán integral relation for solving problems of boundary layer flow and skin friction.

During 1914-18 von Kármán served as director of research of the Austro-Hungarian Aviation Corps, returning to Aachen after the War.

In 1926 he visited the United States at the invitation of Dr. Robert Millikan of the California Institute of Technology and the Daniel Guggenheim Foundation for the Promotion of Aeronautics. Following a trip around the world, he arranged in 1928 to divide his time between Aachen and the California Institute of Technology. In 1930 he settled permanently in California as director of the Guggenheim Aeronautical Laboratory, becoming a U.S. citizen in 1936.
In the nineteen years of his association with the California Institute of Technology, von Kármán published some fifty communications in solid and fluid mechanics, alone and with his students. These included contributions to the theory of the buckling of spherical shells under external pressure, influence of curvature on the buckling characteristics of structures, the Kármán-Moore slenderbody theory for bodies of revolution at supersonic speed, compressibility effects, supersonic aerodynamics, statistical theory of turbulence, and many others.

In 1939 von Kármán initiated rocket research at the Guggenheim Aeronautical Laboratory, especially for the development of assisted take-off rockets for airplanes. He directed the jet propulsion project, which later became the Jet Propulsion Laboratory. With a few friends he founded the Aerojet Engineering Corporation, the first American firm specifically engaged in rocket development in the United States.

Von Kármán took leave of absence in 1944 to organize a Scientific Advisory Group for General H. H. Arnold to analyse the use of science in warfare and to forecast the impact of new developments in rockets, jet propulsion, and supersonic flow on future air warfare. He retired from the California Institute of Technology in 1949, devoting much of his time to his duties as chairman of the U.S. Air Force Scientific Advisory Board, which succeeded the Scientific Advisory Group.

In 1951 von Kármán called a meeting of the directors of aeronautical research of the NATO countries, which resulted in the establishment of the NATO Advisory Group for Aeronautical Research and Development (AGARD) with headquarters in Paris. He was chairman of AGARD until his death.

Von Kármán was a leader in the organization of three additional agencies for international co-operation in science, the International Congress of Applied Mechanics, first held at Delft in 1924 following a preliminary meeting at Innsbruck, the International Congress of the Aeronautical Sciences, first held in Madrid in 1958, and the International Academy of Astronautics established within the International Aeronautical Federation.

Von Kármán was a foreign member of the Royal Society of London, a member of the U.S. National Academy of Sciences, Academie de Sciences de l'Institut de France, Academia Nazionale dei Lincei, Royal Academy of Sciences (Madrid), honorary Fellow of the Royal Aeronautical Society and honorary Fellow, honorary member or member of some additional 35 professional societies in 11 countries. He received more than 60 honorary degrees or special awards from institutions in 13 countries, including the U.S. Medal for Merit (1946), 
John Fritz Medal (1948), Franklin Gold Medal (1948), Lord Kelvin Gold Medal (1950), Gold Medal, Royal Aeronautical Society (1952), Wright Brothers Memorial Trophy (1954), Daniel Guggenheim Gold Medal (1955), U.S. Air Force Exceptional Civilian Award (1955), U.S. Medal of Freedom (1956), Ludwig Prandtl Ring Award of the Wissenschaftlische Gesellschaft für Luftfahrt (1956), Goddard Gold Medal (1960), U.S. National Science Medal (1963).

Theodore von Kármán died during a visit to Aachen on May 7, 1963, four days before his eighty-second birthday. His place as a leader in applied mechanics and aeronautical and astronautical science, and in international co-operation in science and engineering, will not soon be filled.

HUGH L. DRYDEN

\section{Dr. H. Baines}

Dr. Harry Baines, of Messrs. Kodak, Ltd., died suddenly on June 7.

Dr. Baines was an outstanding figure in the photographic world, where he was extremely popular not only for his wide scientific knowledge, but also for his very happy and genial personality.

Born in 1901 of Yorkshire parentage, Harry Baines spent his youth in Nottingham, where he studied chemistry under the late Prof. F. S. Kipping. He took a University of London external B.Sc. degree with firstclass honours in chemistry in 1921 and M.Sc. in 1923, in which year he entered the photographic industry as research chemist to Thomas Illingworth and Co., Ltd. In 1938 he was appointed chief chemist and deputy director of research in Kodak, Ltd., and in 1953 transferred to the head office in Kingsway, London, where he was scientific liaison officer between Kodak, Ltd., and the Press.

He was always keenly interested in raising the standard of photography in Britain, and for the past three years he was responsible for the successful organization of the Kodak scholarships in colour and advanced photography.

His main contributions to photographic science were the devising of a number of new methods of analysis (which formed the basis of a thesis for D.Sc. (London) in 1928), advances in emulsion-making technology and the elucidation of the mechanism of fixation.

He was considerably interested in the work of scientific societies and had been vice-president of the Royal Institute of Chemistry and of the Society of Chemical Industry; but he was more elosely connected with the Royal Photographic Society, of which he was twice president. In 1956 he gave the Royal Institution Christmas Lectures. He was the author of The Science of Photography, which quickly became a popular standard work of reference.

Among the appointments he held at the time of his death were principal of the London School of Medical Photography, chairman of the Photographic Information Council and member of the Photographic Advisory Committee of the City and Guilds of London Institute.

His leisure time interests included antique furniture and clocks and he was a member of the Antiquarian Horological Society.

Dr. Baines leaves a widow and two daughters.

\section{NEWS and VIEWS}

\section{U.S. Presidential Award and Gold Medal :}

Prof. F. L. Whipple

Prof. Fred L. Whipple, director of the Smithsonian Astrophysical Observatory, Cambridge, Mass., has been given the Presidential Award and Gold Medal for Distinguished Federal Civilian Service. The Award, the highest that can be bestowed on a career Federal employee, is being given to Dr. Whipple for his outstanding achievement in conceiving and developing "an optical satellite tracking system which stood ready to track the first artificial satellite launched and has since provided valuable scientific data". This network of twelve tracking stations, located on six continents, is still the most accurate tracking system in operation anywhere in the world. Dr. Whipple, who is also a professor of astronomy in Harvard University, has made major contributions to investigations of comets and meteors. He was the first person to propose that a 'meteor bumper' be placed about a spaceship to protect space travellers and astronauts from the danger of meteor punctures of a spacecraft. This proposal was made in 1946, eleven years before the first satellite was launched and fifteen years before the first man was placed in orbit.

\section{Light Division at the National Physical Laboratory:}

Dr. L. A. SAYCE, who was appointed in 1948 to the position of superintendent of the Light Division at the National Physical Laboratory, retires from this position on June 30 after fifteen years of distinguished service. He took a particular interest in the blending of basic and applied research, and nowhere was this more ably demonstrated than in his personal research on diffraction gratings. During his tenure of office, the Light Division has carried out much basic research on vision, colour and colour rendering, and there have been equally important advances in the more general fields of photometry, radiometry and optics, including the development of new forms of optical masers. The work on diffraction gratings which Dr. Sayce personally supervised has led to the availability of gratings of high efficiency both in the infra-red and $\mathrm{X}$-ray regions, and out of this work an entirely new application of gratings has developed in their use as accurate scales of measurement. This has required a close study of moiré fringe techniques and has resulted in the extensive use of gratings in metrology and engineering. (He will be continuing and extending this aspect of his work for a further period in a special post which has been created for him at the National Engineering Laboratory.) Graduating from King's College, Newcastle upon Tyne, in 1922, Dr. Sayce took his Ph.D. in 1925. He was appointed lecturer in chemistry there in 1927, and his researches thereafter covered a wide range of interest in physical and inorganic chemistry, instrument design and photography. During the Second World War he served in the Ministry of Horme Security, and for two years before joining the National Physical Laboratory, in 1948, he was assistant director of physical research at the Admiralty. $\mathrm{He}$ was created C.B.E. in 1958. Dr. Sayce is to be succeeded as superintendent of the Light Division by Dr. J. Dyson (see Nature, 198, 738; 1963).

Chemistry at Sheffield: Prof. R. D. Haworth, F.R.S.

Prof. R. D. Haworth retires from the Firth professorship of chemistry in the University of Sheffield at the end of this academic year. $\mathrm{He}$ had his early education in Stockport and then at the University of Manchester, where he came under the lasting influence of Arthur Lapworth. He proceeded with an 1851 Exhibition Scholarship to Oxford, to conduct very fruitful work on the synthesis of the isoquinoline alkaloids. From 1937 until 1939 he was lecturer in chemistry at King's College, Newcastle upon Tyne, where he carried out his extensive 